\title{
Erratum
}

\section{Analysis of emergency department length of stay for mental health visits: a case study of a Canadian academic hospital - ERRATUM}

\author{
Deyvison T. Baia Medeiros; Shoshana Hahn-Goldberg; Erin O'Connor; Dionne M. Aleman
}

doi: $10.1017 /$ cem.2018.417

The original publication of this article contained extraneous text as a result of a typesetting error. The article has been updated to correct this mistake.

\section{REFERENCE}

Baia Medeiros DT, Hahn-Goldberg S, O'Connor E and Aleman DM. Analysis of emergency department length of stay for mental health visits: a case study of a Canadian academic hospital CFEM 2019;21(3): 374-383. 